\title{
PSYCHE
}

Vol. 84

September-December, 1977

No. 3-4

\section{DISPERSAL BEHAVIOR OF HONEY BEE SWARMS*}

\author{
By Thomas D. Seeley and Roger A. Morse
}

Museum of Comparative Zoology

Harvard University, Cambridge, Massachusetts 02138

and Department of Entomology

Cornell University, Ithaca, New York 14853

\section{INTRODUCTION}

Food shortages were probably a major ecological force upon the European races of honey bees (Apis mellifera) in their natural habitat of temperate deciduous forest. And many features of honey bee biology are reasonably interpreted as techniques of competition for food. For example, the demographic properties of descendant honey bee colonies in North America, such as low reproductive rate and infrequent but expensive offspring, probably reflect selection for competitive ability rather than productivity (Seeley 1978). Also the honey bee's sophisticated recruitment system involving dance language and olfactory recruitment (von Frisch 1967, Gould 1975) seems ideal for a "scramble" type competitive device involving rapid discovery and exploitation of food sources. Furthermore bees from different colonies will fight at feeding dishes when the food is in short supply (Kalmus 1941) and will reduce each others' foraging range (Levin 1961, Levin and Glowska-Konopacka 1963, Gary et al. 1972, 1973, 1975). Thus honey bee colonies can apparently also compete for food sources using techniques of "contest" competition.

*Manuscript received by the editor March 15, 1978. 
Behaviors promoting colony spacing are another line of adaptations to limited food supplies and are widespread among the social insects (Brian 1965, Wilson 1971). For honey bees these behaviors fall logically into two classes: (1) attack by established colonies upon adjacent colonies, and (2) avoidance of established colonies by swarms when selecting nest sites. Behavior of the first category is apparently of minor importance with honey bees since bee colonies can be crowded into peaceful apiaries. However strong colonies occasionally plunder nearby weak colonies. Regarding the second category, Lindauer (1955) provides evidence suggesting that honey bee swarms avoid their parent colonies by selecting new nest sites at least a few hundred meters from the original nest. Given the importance of understanding colony spacing to a clear understanding of honey bee ecology, especially intraspecific foraging competition, we decided to investigate the dispersal behavior of honey bee swarms.

\section{MATERIALS AND METHODS}

The honey bees used in this study came from the Dyce Honey Bee Laboratory, Cornell University, and were hybrids of the European races of honey bees imported for American apiculture. These races include primarily Apis mellifera ligustica Spinola, A. m. caucasica Gorbatschew, A. m. carnica Pollmann and A. m. mellifera L. (Ruttner 1975). The study of swarm dispersal distance was conducted during the summers of 1976 and 1977 on Mount Pleasant, a large area of mature forest near Ithaca, New York. The test of swarms' preferred dispersal distance was performed during December, 1977 and January, 1978 at the Archbold Biological Station, Lake Placid, Florida. There the study area consisted of a sandy plain which extends for many kilometers and which is primarily covered by scrubby vegetation. The widely dispersed pine trees in this area offer very few, if any, natural nest sites for honey bees. Additional methodological details will be given with the descriptions of the individual experiments.

\section{EXPERIMENTS AND RESULTS}

\section{Distribution of Swarm Dispersal Distances}

Upon departing its parent colony, a honey bee swarm flies only a few tens of meters before assembling to form a hanging swarm 
cluster (Ambrose 1974). Scout bees fly from this cluster in search of a nest site and later recruit other scouts to newly discovered nest sites using the dance language (Lindauer 1955). These communication dances are conspicuously performed on the surface of the swarm. Thus one can measure approximately how far swarms move between parent and new colony sites by reading the recruitment dances of the scout bees on swarms.

We used artificial swarms of honey bees which were prepared as follows. First, worker bees were shaken off frames of a beehive into a swarm cage $(15 \times 25 \times 35 \mathrm{~cm})$ of wood and wire screen sides using a large funnel. Then the swarm's queen was removed from the beehive and confined in a standard queen mailing cage $(3.2 \times$ $10 \times 1.6 \mathrm{~cm}$ ) which was suspended amidst the worker bees in the larger swarm cage. The bees were kept confined and liberally fed with a $50 \%$ sucrose solution for at least 24 hours. Bees treated in this way behave like a natural swarm. If placed near their parent hive, they do not return to it but instead search for a new nest site. We controlled swarm size by weighing the workers shaken into the swarm cage. The swarms all weighed approximately $2 \mathrm{~kg}$ (about 15,000 bees), a typical size for natural swarms (Fell et al. 1977).

Each swarm was placed on a wood cross $(120 \mathrm{~cm}$ high with a 46 $\mathrm{cm}$ long cross member) in the study area by tying the caged queen to the cross. The worker bees, upon being shaken from the swarm cage, would cluster about the caged queen. A 1-liter, gravity feeder jar provided sugar syrup continuously for each swarm. We positioned the swarms in a small clearing surrounded by forest for at least $1 \mathrm{~km}$ and generally 2 or more $\mathrm{km}$. Thus the swarms were surrounded at both small and large distances by a presumably random distribution of natural nest sites. The swarms were run one at a time, except for three swarms which we observed simultaneously. The three concurrently run swarms were positioned at least $30 \mathrm{~m}$ from each other.

We followed each swarm's selection of a nest site from start to finish by reading the scout bees' dances to determine the distances and directions to the nesting sites they had discovered. The calibration curves of von Frisch (1967) and Lindauer (1971) for Apis mellifera ligustica were used to translate dance tempos into distances to the advertised nest sites. The dances representing the site finally selected by each swarm were easily recognized by the frenzy with which they were performed and by their heavy preponderance 


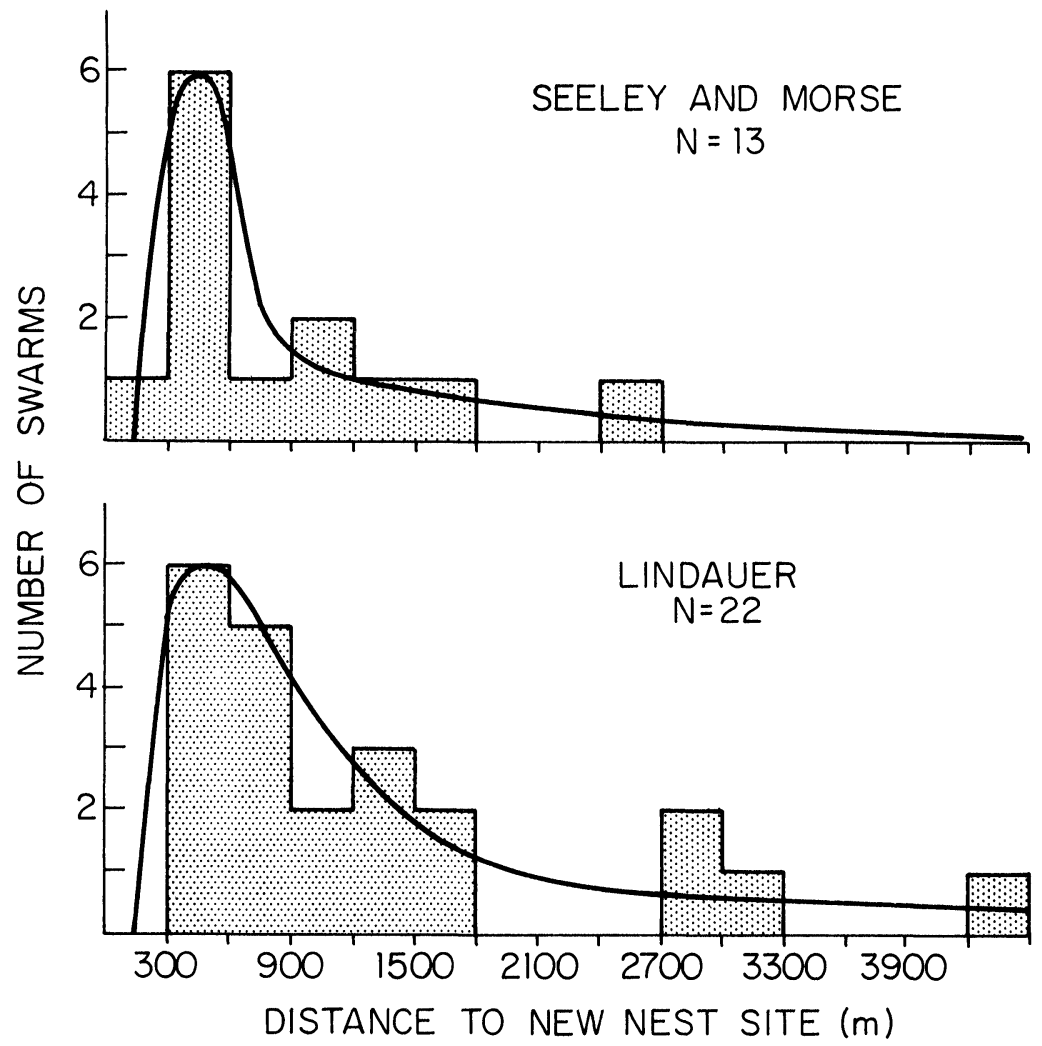

Fig. 1. Distributions of distances from swarm cluster sites to new nest sites, as calculated from the recruitment dances of scout bees on swarms. The curves are least-squares fits to points centered in the top of the histogram bars. Upper figure is original data; lower figure is after Table 1 in Lindauer (1955).

over all other dances just before each swarm lifted off to fly to its chosen site.

The results from observing 13 swarms are shown in Fig. 1. This figure also includes data gathered in similar fashion by Lindauer (1955) who observed swarms inside Munich and in various rural locations in West Germany. The curves in Fig. 1 were fitted to the histograms as described in Seeley and Morse (1978). The striking features of the two distributions are (1) their similarity despite widely separated study areas, and (2) the low frequency of swarms 
travelling less than $300 \mathrm{~m}$ to a new nest site. This pattern may simply reflect the smaller number of nest sites within a small radius area relative to a large radius area. But it could also represent a preference by swarms for nest sites beyond 300 meters from their cluster sites. Since swarms generally travel only a few tens of meters from the parent colony before settling at an interim cluster site, a preference for nest sites far beyond the cluster site would promote the dispersion of parent and daughter colonies. The following section reports a test for this preference.

\section{Test of Preference for Distant Nest Sites}

To test whether swarms prefer distant nest sites, we offered swarms a choice between two nestboxes which were constructed and positioned as identically as possible, but with one 20 and the other $400 \mathrm{~m}$ from each swarm's cluster site. These distances correspond to the low end tails and the modes of the distributions in Fig. 1. Lindauer (1955) performed a similar experiment with nestboxes 30 and $250 \mathrm{~m}$ from a swarm. His swarm chose the $250 \mathrm{~m}$ site. However, the lack of repetitions and of controls for differences in nest site exposure, to which bees are highly sensitive, make this experiment's result suggestive rather than conclusive.

The nestboxes for our experiment were nailed onto two very similar sand pines $380 \mathrm{~m}$ apart. Each nestbox was cube-shaped, 40 liters in volume, and had a $3 \mathrm{~cm}$ diameter entrance hole positioned midway across the front, $8 \mathrm{~cm}$ up from the nestbox floor. A nail driven horizontally across the entrance prevented occupation by birds. The nestboxes were constructed of $1.5 \mathrm{~cm}$ thick plywood and were painted dark green on the outside. Nestbox floors were removable to permit interior inspections. The seam between the floor and the walls of each nestbox was sealed with opaque photographic tape. The entrance of both nestboxes faced south and was $3.75 \mathrm{~m}$ above the ground. The wind, sun and rain exposures of both nestboxes were carefully matched by trimming off branches about the nestboxes and by nailing a shade board $(56 \times 100 \mathrm{~cm})$ atop each nestbox.

Each trial of the test was started by introducing a colony of bees into the study area, positioning it $30 \mathrm{~m}$ from one of the nestboxes as shown in Fig. 2. We left each colony undisturbed for at least two days of good weather to provide time for the colony's orientation to its new home range. On the third day or later an artificial 

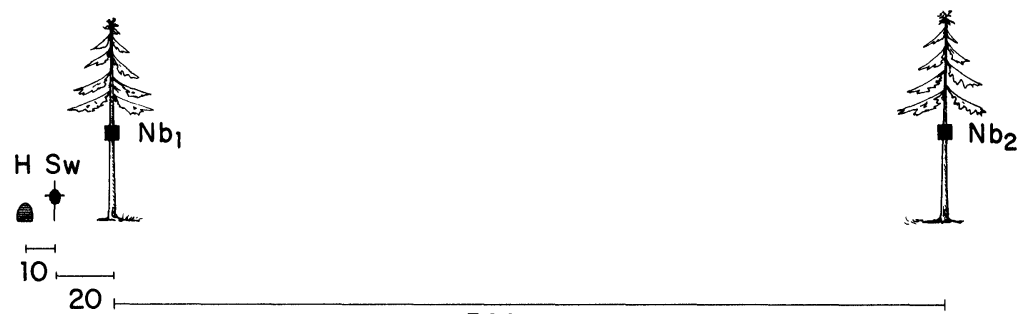

$380 \mathrm{~m}$

Fig. 2. Experimental array for testing preference in swarm dispersal distance. $H$, hive; $S w$, swarm on wooden cross; $N b$, nestbox. In the five trials of the test, the hive and swarm were alternately positioned near nestbox 1 or nestbox 2 , always maintaining the distance relationships shown. All distances are in meters. The objects in this figure and the spacings between objects are not drawn to the same scale.

swarm was prepared from the hive as described above, but with the difference that each swarm was confined and fed in the swarm cage for only one hour. Following this brief confinement each swarm was placed on a wooden cross located between the parent hive and the nearby nestbox, $10 \mathrm{~m}$ from the former and $20 \mathrm{~m}$ from the latter. Thus a swarm cluster was established a natural distance from its parent colony and 20 and $400 \mathrm{~m}$ from two otherwise closely matched nest sites, as shown in Fig. 2. The parent hive and swarm were placed at opposite ends of the nestbox array on alternate trials. This provided control for possible differences between the nestboxes besides distance from the swarm.

We monitored each swarm's selection of a nest site by reading the recruitment dances as described above. But besides following the dances on the swarm, we periodically (at least hourly) measured the number of scout bees visible at each nestbox by making 10 counts, each count 15 seconds apart, while standing directly in front of a nestbox. Both near and far nestboxes were always rapidly discovered by the scout bees. Each morning, before the bees started flying, we inspected the interior of both nestboxes. Often 2 to 10 ants were found in the nestboxes and were promptly removed and killed. One morning during the second trial a complete ant colony (queen, workers and brood) was discovered in the far nestbox. This nestbox was quickly sealed with the ants inside, removed and replaced with a new nestbox. This was the only nestbox change performed during the experiment. 
Table 1. Outcomes of five choices by honey bee swarms between near and far nestboxes.

\begin{tabular}{cccc}
\hline Trial & $\begin{array}{c}\text { Nestbox } \\
\text { Near Swarm }\end{array}$ & $\begin{array}{c}\text { Nestbox } \\
\text { Chosen }\end{array}$ & $\begin{array}{c}\text { Distance to } \\
\text { Selected Nestbox (m) }\end{array}$ \\
\hline 1 & 1 & 1 & 20 \\
2 & 2 & 2 & 20 \\
3 & 1 & 1 & 20 \\
4 & 2 & 2 & 20 \\
5 & 1 & 2 & 400 \\
\hline
\end{tabular}

We prevented swarms from occupying the nestboxes by keeping each swarm's queen caged on the wooden cross in a standard queen mailing cage. Every swarm's attempt to move to a nestbox ended with its return to the caged queen. But even though swarms never occupied the nestboxes, their nestbox preferences were always clearly indicated by large differences in the number of dances for and scouts at the two nestboxes.

The outcomes of five swarms' selections of a nest site are shown in Table 1. Apparently the nestboxes 1 and 2 were well matched, because with 2 and 3 selections respectively, no significant preference for either nestbox was shown. More important was the pattern of choice between near and far nestboxes: 4 to 1 , respectively. The estimated probability of a swarm choosing the near nestbox is 0.80 and the $95 \%$ confidence limits on this probability are 0.48 and 0.95 . Thus these results do not support the hypothesis that swarms prefer distant nest sites. Instead, they suggest that swarms prefer nearby nest sites. Unfortunately, because of lack of time, we were unable to perform further trials of this experiment.

The one selection of the distant nest site may not even be a valid test result. For in the fifth trial the swarm's choice between the nestboxes proceeded differently than with the previous four swarms. As is shown in Fig. 3, this swarm's preference developed initially in favor of the near nestbox and reached a point at which we expected the swarm to lift off and attempt moving to the near nestbox. Then suddenly the situation reversed. The scouts decreased at the near nestbox and increased at the far nestbox. Finally the swarm lifted off and flew past the near nestbox en route to the far nestbox. In the previous four trials, each swarm's preference between nestboxes 


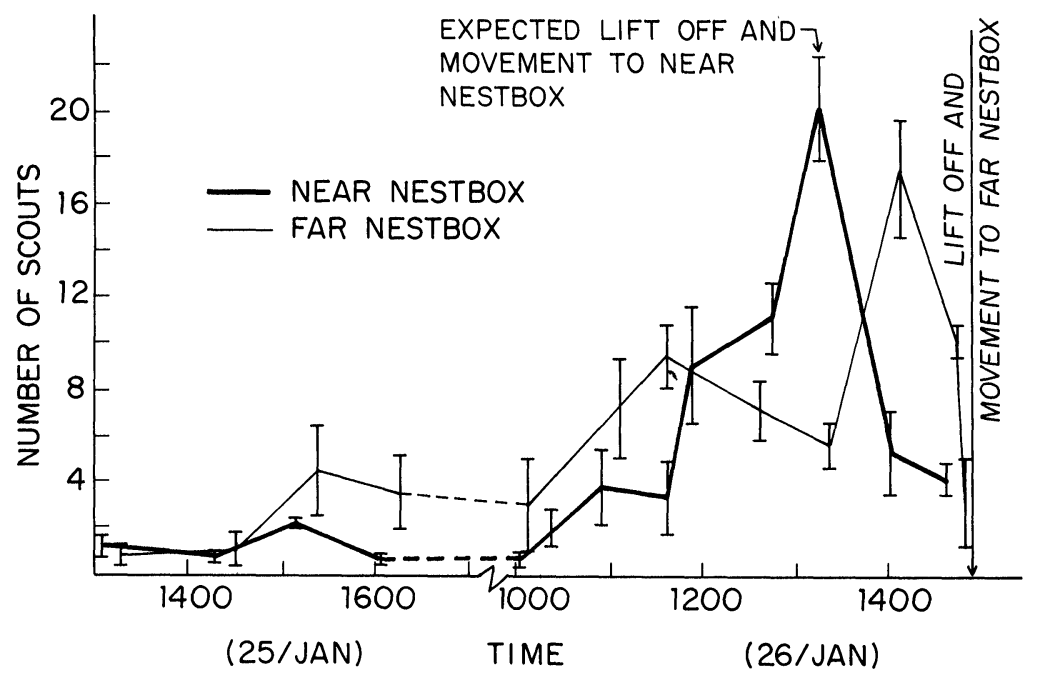

Fig. 3. Record from the fifth trial of a swarm's selection between near and far nestboxes, as monitored by counting the scouts visible at each nestbox. Vertical bars denote plus and minus one standard deviation for 10 counts at 15 second intervals.

developed smoothly and steadily in favor of the nestbox which was ultimately chosen. Moreover, when we inspected both nestboxes shortly after the lift-off in the fifth trial, we found the far nestbox empty inside except for a few scout bees, but we discovered four ants in the near nestbox. Similar nestbox inspections in the previous four trials had not disclosed any ants in either nestbox. These observations suggest that ants interfered in the fifth trial by entering the near nestbox. If so, then this may have created a difference in the nestboxes' qualities which outweighed any quality difference based upon the nestboxes' different distances from the swarm.

\section{DISCUSSION}

The two experiments reported here appear to give conflicting results concerning the dispersal behavior of honey bee swarms. In the first experiment we observed swarms generally travelling a large distance, at least 300 meters, to new home sites. But in the second experiment, wherein we provided nest sites at 20 and 400 meters, the swarms showed no preference for the more distant nest site. This difference in dispersal behavior probably does not reflect differences between the bees used in the experiments. In both ex- 
periments the bees came from the same source, the apiaries of Dyce Laboratory, and in both experiments the bees were prepared as artificial swarms using nearly identical techniques. We suspect the disparity in experimental outcomes simply reflects a lack of nearby nest sites in the first experiment which forced the swarms to choose distant nest sites. If so, then our findings suggest that in nature the spacing out of feral honey bee colonies is based more upon the dispersion of suitable nest sites than upon programmed dispersal behavior in honey bee swarms.

Our findings also suggest that swarms prefer moving only a short distance to a new home site. Minimizing dispersal distance may be advantageous to swarms in reducing the hazard of losing poor flying queens. It might also help keep the daughter colony near the closely related, and thus perhaps minimally aggressive, mother colony. Robbing and foraging range restriction are probably the most common forms of aggression between bee colonies. Furthermore, because the honey bee's flying ability enables it to forage over very large areas, colony dispersal may not significantly reduce the competition, if any, between colonies for food.

We close this report by stating a possible weakness of this study: use of artificial swarms. Because this study's experiments required many repetitions, they would have proceeded exceedingly slowly had we used only swarms emerging naturally from colonies placed at the study sites. Thus we used the readily available artificial swarms. And these swarms appear to behave normally while selecting a nest site. They form a quiet cluster, dispatch scouts which discover and select the new home site, and finally fly to the chosen site. However, if a swarm's dispersal behavior is stimulated by its scouts' close familiarity with the surrounding region or is dependent upon the natural process of swarm formation, then our artificial swarms would have shown abnormal dispersal behavior.

\section{ACKNOWLEDGMENTS}

We thank Richard Nowogrodzki for field assistance and the Archbold Biological Station for the use of their research facilities. Bert Hölldobler critically reviewed the manuscript. Supported by the National Science Foundation (Grant No. BMS 76-15008), and the Anderson Fund and the Parker Fellowship, both of Harvard University. 


\section{SUMMARY}

Insofar as normal honey bee behavior was observed in these studies with artificial swarms, our results indicate that swarms frequently move at least 300 meters from their parent colony to a new nest site, but that they do not prefer nest sites far from their parent colonies. Instead, swarms may prefer a nest site which is near the parent colony. Therefore the spacing of suitable nest sites appears to be a major determinant of the spacing of feral honey bee colonies, and behaviors promoting colony spacing to reduce foraging competition may not exist in the European races of honey bees.

\section{REFERENCES}

AMbrose, J. T.

1975. A study of honey bee (Apis mellifera L.) swarms while in transit to a new homesite. Ph.D. thesis, Cornell Univ., Ithaca, N. Y.

BRIAN, M. V.

1965. Social insect populations. Academic Press, London and New York, $135 \mathrm{pp}$.

Fell, R. D., J. T. Ambrose, D. M. Burgett, D. DeJong, R. A. Morse and T. D. SEELEY

1977. The seasonal cycle of swarming in honey bees. J. apic. Res. 16, 170173.

FRISCH, K. vON

1967. The dance language and orientation of bees. Belknap Press of Harvard University Press, Cambridge, Mass., 566 pp.

Gary, N. E., P. C. Witherell AND J. Marston

1972. Foraging range and distribution of honey bees used for carrot and onion population. Environ. Entomol. 1, 71-78.

Gary, N. E., P. C. Witherell and J. M. Marston

1973. Distribution of foraging bees used to pollinate alfalfa. Environ. Entomol. 2, 573-578.

Gary, N. E., P. C. Witherell and J. M. Marston

1975. The distribution of foraging honey bees from colonies used for honeydew melon pollination. Environ. Entomol. 4, 277-281.

GoulD, J. L.

1975. Honey bee recruitment: the dance-language controversy. Science 189, 685-693.

Kalmus, $\mathrm{H}$.

1941. Defence of source of food by bees. Nature 148, 228.

LEVIN, M. D.

1961. Interactions among foraging honeybees from different apiaries in the same field. Insectes sociaux 8, 195-201.

LEVIN, M. D. AND S. GlowsKa-KonopaCKA

1963. Responses of foraging honeybees in alfalfa to increasing competition from other colonies. J. apic. Res. 2, 33-42. 
LINDAUER, $\mathrm{M}$.

1955. Schwarmbienen auf Wohnungssuche. Z. vergl. Physiol. 37, 263-324. LINDAUER, M.

1971. Communication among social bees. Harvard University Press, Cambridge, Mass., $161 \mathrm{pp}$.

RUTTNER, F.

1975. Races of bees, pp. 19-38 In Dadant and Sons (Eds.), The hive and the honey bee. Dadant, Hamilton, Ill., 740 pp.

SEELEY, T. D.

1978. Life history strategy of the honey bee, Apis mellifera. Oecologia. 32, 109-118.

SeEley, T. D. AND R. A. Morse

1978. Nest site selection by the honey bee, Apis mellifera. Insectes sociaux. In press.

WILSON, E. O.

1971. The insect societies. Belknap Press of Harvard University Press, Cambridge, Mass., $548 \mathrm{pp}$. 

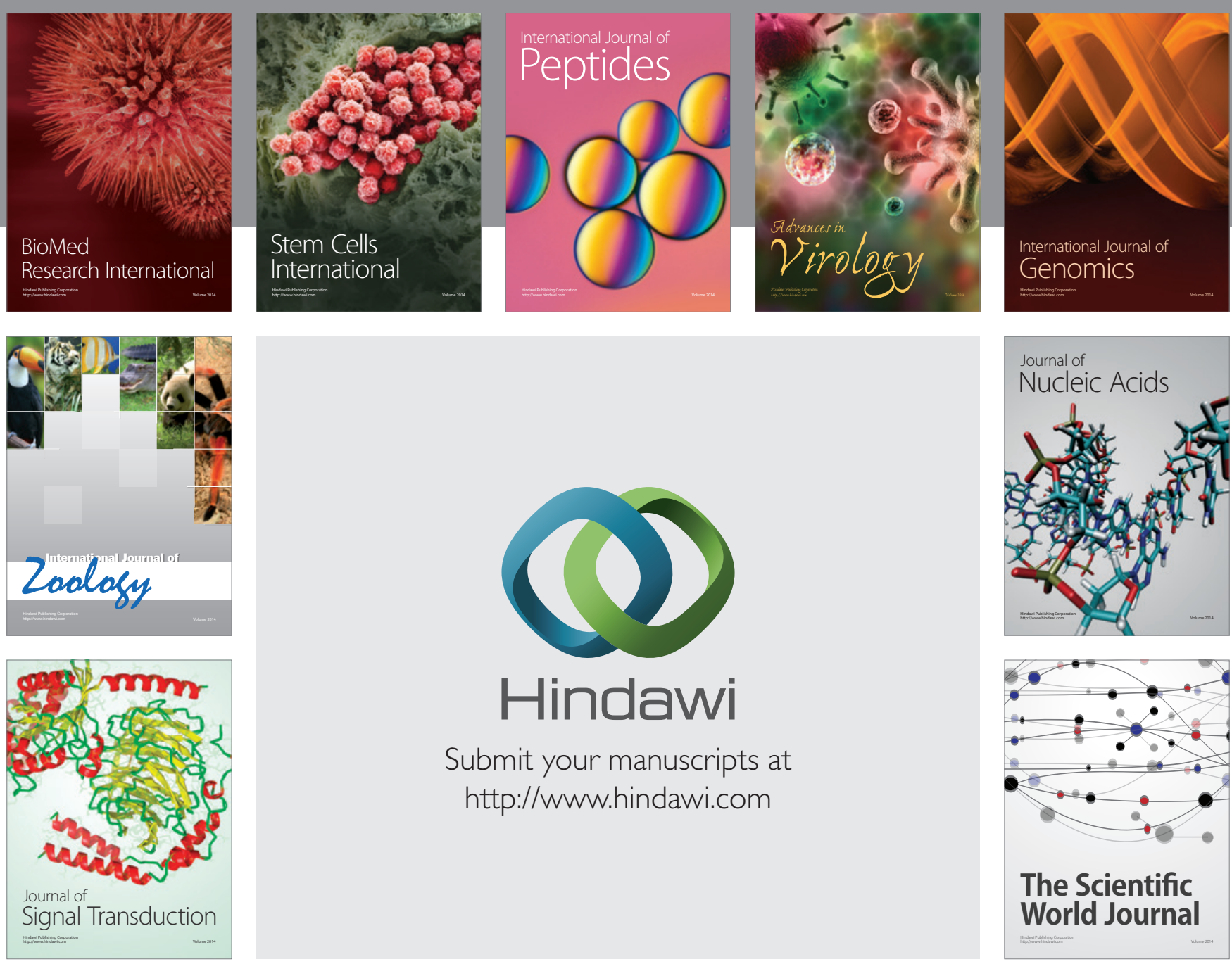

Submit your manuscripts at

http://www.hindawi.com
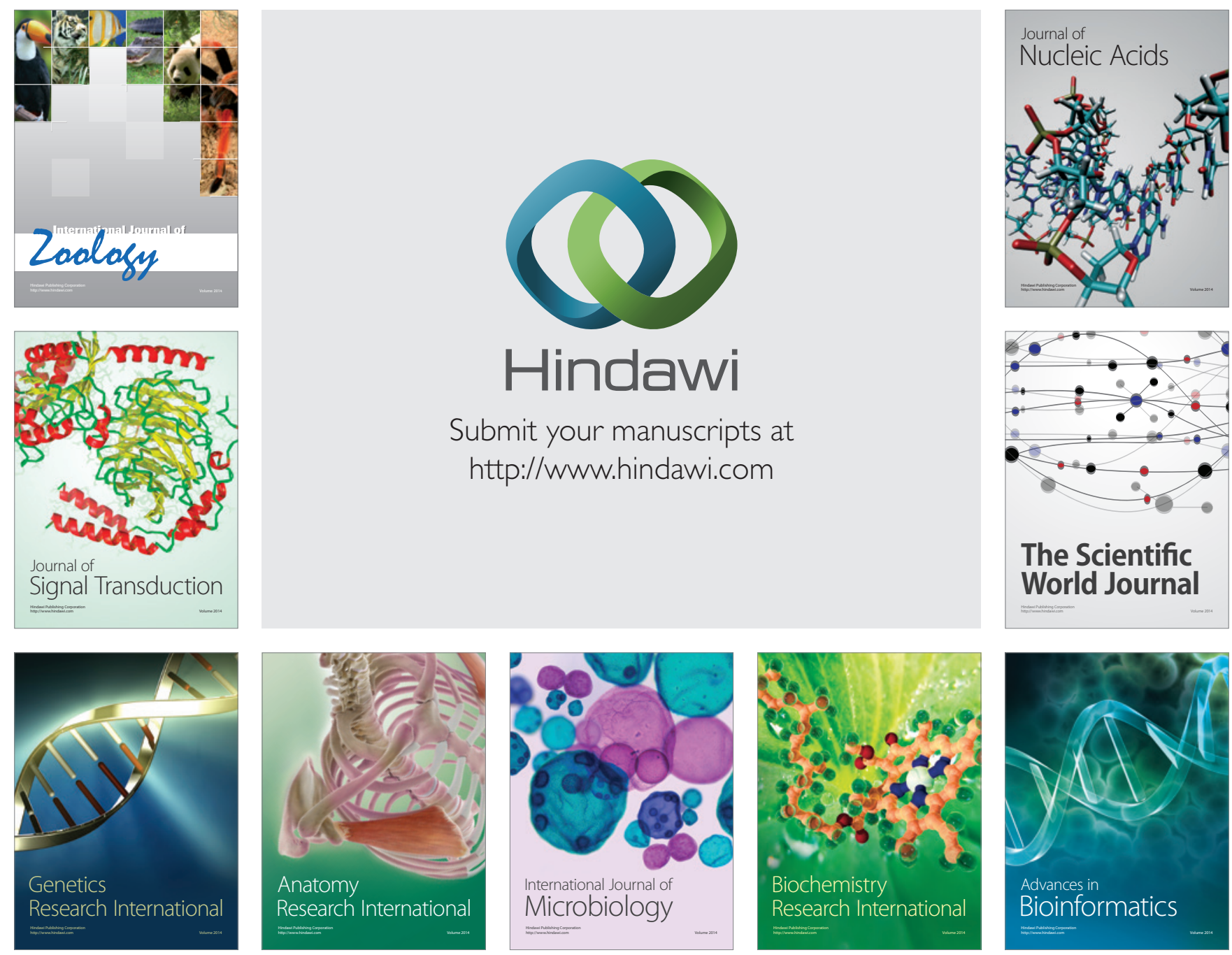

The Scientific World Journal
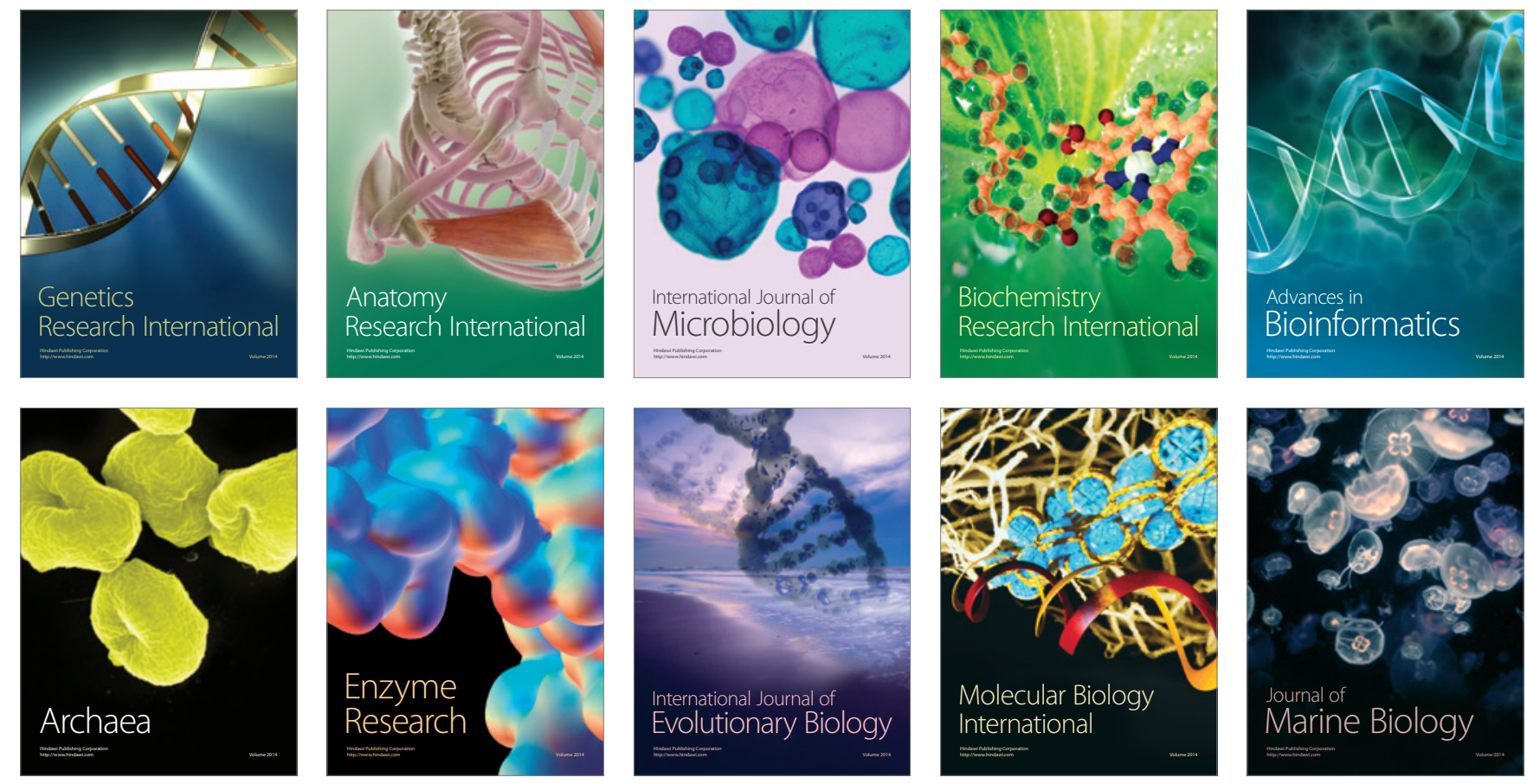